\title{
A comparison of the effects of the dopamine partial agonists aripiprazole and (-)-3-PPP with quinpirole on stimulated dopamine release in the rat striatum: studies using fast cyclic voltammetry in vitro
}

\author{
${ }^{1,2}$ O’Connor, John J., ${ }^{1}$ Lowry, John P, \\ ${ }^{1}$ Department of Chemistry, National University of Ireland \\ Maynooth, Ireland \\ ${ }^{2}$ UCD School of Biomolecular \& Biomedical Science, \\ UCD Conway Institute, Belfield, Dublin 4, Ireland.
}

Correspondence:

John J. O'Connor

UCD School of Biomolecular \& Biomedical Science,

UCD Conway Institute Belfield, Dublin 4,

Ireland

Tel: 0035317166765

Email: john.oconnor@ucd.ie of the compound in question to inhibit the effect of a full agonist such as quinpirole on dopamine release (Limberger et al., 1991).

Aripiprazole is an atypical antipsychotic and antidepressant used in the treatment of schizophrenia, bipolar disorder, and clinical depression. Aripiprazole's mechanism of action is different from those of other FDA-approved atypical antipsychotics (e.g., clozapine, olanzapine, quetiapine, ziprasidone, and risperidone). Rather than antagonizing the dopamine $\mathrm{D}_{2}$ receptor, aripiprazole acts as a dopamine $\mathrm{D}_{2}$ and $5-\mathrm{HT}_{1 \mathrm{~A}}$ receptor partial agonist $\left(\mathrm{K}_{\mathrm{i}}=0.34 \mathrm{nM}\right.$ and $1.65 \mathrm{nM}$ respectively, Lawler et al., 1999). It can significantly increase dopamine levels in the prefrontal cortex of rats but only at low concentrations (Zocchi et al., 2005).

(-)-3-PPP has also been shown to have some antipsychotic action but not sustained receptor desensitization. It has been used in schizophrenia possibly by attenuating dopamine function in two different ways, by stimulating the presynaptic receptors and blocking the postsynaptic receptors. It has previously been reported that in contrast to racemic 3-PPP, (+)-3-PPP can inhibit electrically evoked release of both $\left[{ }^{3} \mathrm{H}\right]$ dopamine and $\left[{ }^{14} \mathrm{C}\right]$ acetylcholine from superfused rat neostriatal slices (Mulder et al., 1985). In contrast (-)-3-PPP did not have inhibitory effects on dopamine release but antagonized those effects of (+)-3-PPP. Both enantiomers can reduce increases in striatal dopamine synthesis produced by $\gamma$-butyrolactone, although the (-)enantiomer was only partially active (Clark et al., 1984). 3-PPP has also been shown not to protect against MPTP-induced dopaminergic neurotoxicity (Muralikrishnan et al., 2004). In contrast to the above compounds quinpirole has previously been shown by us and other groups to act as a full agonist inhibiting dopamine release in the rat striatum with high potency (for example see (Palij et al., 1990, O’Neill et al., 2009).

The determination of the functional intrinsic activity of partial agonist compounds at dopamine $\mathrm{D}_{2}$ receptors is a difficult task when carried out in brain 
native tissues. The aim of the study was to quantify the potential partial agonist and antagonist activity of (-)-3-PPP and the dopamine $\mathrm{D}_{2}$ partial agonist, aripiprazole, on pre-synaptic dopamine $\mathrm{D}_{2}$ autoreceptors located in the terminals of dopamine neurons in the rat striatum using FCV. We have also compared the effect of these compounds with that of the full agonist quinpirole.

\section{Materials and Methods}

\subsection{Electrochemical System}

\subsubsection{Generation of the signal}

Fast cyclic voltammetry (FCV) is an electrochemical technique designed to enable detection of monoamine release in real time (see Stamford, 1990 for a comprehensive review). Its advantages are the speed of recording and the small size of the working electrode (typically $7 \mu \mathrm{m}$ diameter by $50 \mu \mathrm{m}$ length). A three electrode configuaration is typically used in brain slice FCV, namely an auxiliary electrode, working electrode and reference electrode. The reference electrode is a silver/silver chloride electrode (A-M Systems, Inc, WA) whilst the auxiliary electrode is also a $\mathrm{Ag} / \mathrm{AgCl}$ electrode but bridged from the bath in a plastic pipette tip filled with $1 \mathrm{M} \mathrm{NaCl}$. Fast cyclic voltammetry (FCV) was carried out using a Millar Voltammeter (Dr. Julian Millar, Queen Mary \& Westfield College, University of London, UK) connected to an FCV headstage (see Millar and Barnett, 1988 for a full circuit diagram of the apparatus). The FCV amplifier subjects the working electrode to a triphasic set of anodic and cathodic voltage sweeps in a period of $20 \mathrm{~ms}$. The triphasic voltage waveform ramps from 0 to $-1.0 \mathrm{~V}$ to $+1.4 \mathrm{~V}$ to $-1.0 \mathrm{~V}$ to $0(20 \mathrm{~ms})$ equating to a scan of $480 \mathrm{~V} / \mathrm{s}$. Throughout our experiments this waveform was applied to the potentiostat four times a second. Because the scan only lasts $20 \mathrm{~ms}$, it can be repeated many times a second if required. The input triphasic ramp pattern for FCV in these experiments is shown in Fig. 1A. The FCV headstage circuit measures the working electrode current (generated by the drive voltage) and from this current the concentration of electrically oxidizable or 'electroactive' material at the tip of the working electrode can be computed.

\subsubsection{Faradaic current}

Following the triphasic voltage input into the working electrode a background current is monitored that is due to the complex impedance characteristics of the electrode/ electrolyte interface (Fig. 1B). When electroactive materials such as dopamine are present on the surface of the electrode extra current flow is generated through the electrode. This electron influx is known as the faradaic current (Fig. 1C) and includes both oxidation and reduction peaks, for dopamine, characteristically $+600 \mathrm{mV}$ and $-200 \mathrm{mV}$ respectively. To provide information on dopamine release dynamics, a sample and hold circuit was set to monitor current at $+600 \mathrm{mV}$ on each successive scan. The typical output from this display in shown in Fig. 1D in response to dopamine.

\subsubsection{Carbon fiber electrode manufacture}

Carbon fiber electrodes were home manufactured but see also Armstrong James \& Millar (1979). A borosilicate capillary tube $(1 \mathrm{~mm}$ i.d.) was filled with acetone and a single carbon fiber inserted (7 $\mu \mathrm{m}$ diameter). Upon drying the tube the capillary was pulled by an electrode-puller (P97, Sutter Instrument, Novato, USA) giving rise to two electrodes both with a glass seal around a single carbon fiber. The exposed length of the fiber was cut back mechanically under a microscope to give rise to an exposed length of approximately $50 \mu \mathrm{m}$. This enables the electrode to measure monoamines such as 5-hydroxtramine (O'Connor \& Kruk, 1991; 1992) and dopamine (Kruk \& O'Connor, 1995) in very specific nuclear regions of the brain.

\subsection{Brain slice preparation}

Male Wistar rats (178-283g) housed 4 to a cage were purchased by NUIM fortnightly from Harlan, UK and kept in the BioResource Unit at NUI Maynooth. All experimental procedures were approved by the Animal Research Ethics Committee of the Biomedical Facility at the National Univesity of Ireland, Maynooth. Rats were killed by decapitation. The brain was quickly removed into ice-cold artifical cerebrospinal fluid. Blocks of tissue containing the caudate putamen and nucleus accumbens were prepared. $350 \mu \mathrm{m}$ thick slices were sectioned using a Campden vibrotome. Brain slices were then transferred to a holding chamber containing artifical cerebrospinal fluid (see below) at room temperature $\left(20-21^{\circ} \mathrm{C}\right)$ to equilibrate for 1 h. A single slice was then transferred to a recording chamber and perfused with oxygenated aCSF at 4 $\mathrm{ml} / \mathrm{min}$ at $30-31^{\circ} \mathrm{C}$ for $40 \mathrm{~min}$ before electrical stimulation.

\subsection{Measurement of endogenous dopamine release}

Following 40 min equilibration, a bipolar tungstenstimulating electrode with a tip separation of 200 $\mu \mathrm{m}$ (A-M Systems, Inc.) was placed in the dorsolateral caudate putamen (see Fig. 1). A carbon fibre electrode as described previously, was placed 100-200 $\mu \mathrm{m}$ from the stimulating electrode. Stimulated dopamine release (using Neurolog modules) was evoked using a square-wave pulse of $10 \mathrm{~V}$ amplitude and $100 \mu$ s duration delivered once every $2 \mathrm{~min}$. A sample and hold output before during and after a stimulus is shown in Fig. 1D. Dopamine release under these conditions is tetrodotoxin-sensitive and $\mathrm{Ca}^{2+}$-dependent (Palij et al., 1990). Sample and hold data was recorded onto a PC via a 4 channel MacLab. Recordings were taken in the dorsomedial striatum (Fig. 1E). 


\subsection{Carbon fiber electrode calibration}

Electrodes were calibrated with increasing concentrations of freshly prepared dopamine in the range $0.05 \mu \mathrm{M}$ to $1 \mu \mathrm{M}$, concentrations in the range of the endogenous dopamine released in the slices. The relationship of the dopamine concentration $(\mu \mathrm{M})$ and the measured faradaic current $(\mathrm{nA})$ was
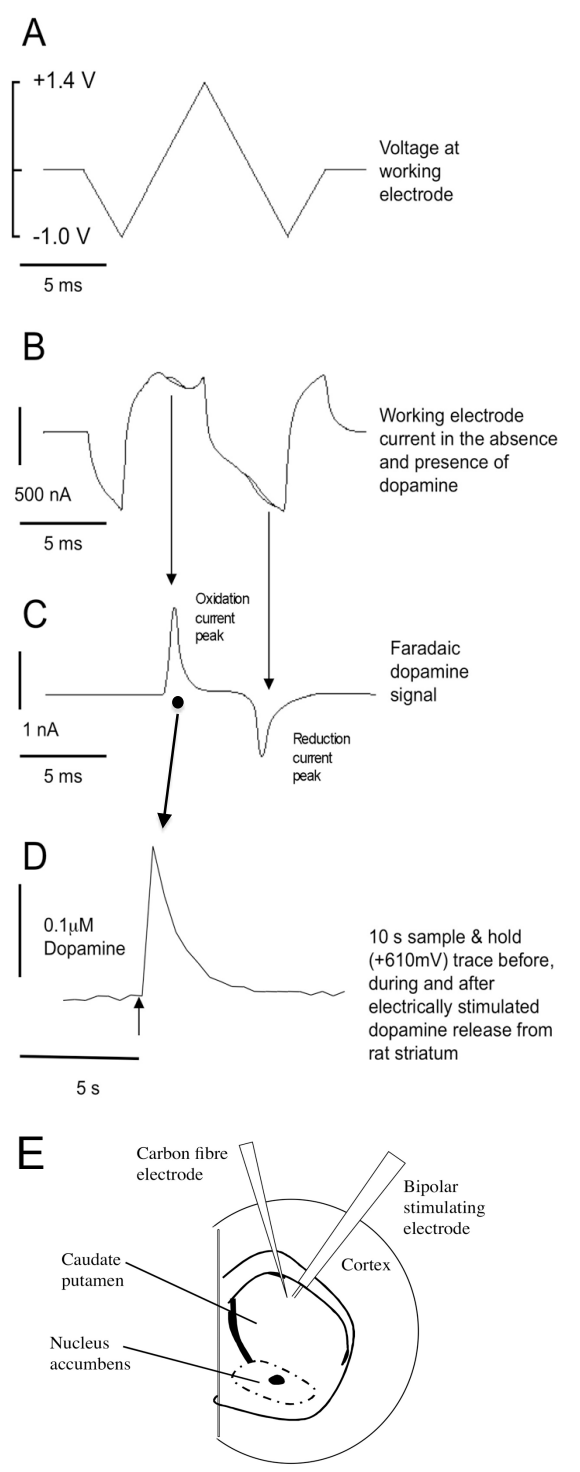

Figure 1. Waveforms used in Fast Cyclic Voltammetry (FCV)

A. A triphasic voltage ramp is passed down the carbon fibre electrode four times per second $(4 \mathrm{~Hz})$. The ramp sweeps from $0 \mathrm{~V}$ (relative to silver/silver chloride reference electrode) to $-1.0 \mathrm{~V}$ to $+1.4 \mathrm{~V}$ to $-1.0 \mathrm{~V}$ and back to $0 \mathrm{~V}$. This sweep lasts $20 \mathrm{~ms}$.

B. The resultant current measured by the carbon fibre electrode in called the charging current. Superimposed on the charging current is the current obtained when the electrode is placed in a ringer solution containing $1 \mu \mathrm{M}$ dopamine.

C. If the charging current in B in the absence of dopamine is subtracted from that current in the presence of dopamine a trace typical of $\mathrm{C}$ is the result (subtractogram). This is known as the faradaic current and is the result of the oxidation and reduction of dopamine on the surface of the carbon fibre electrode. Dopamine oxidizes at approximately $+610 \mathrm{mV}$ and is reduced at approximately $-200 \mathrm{mV}$.

D. The trace illustrated in $\mathrm{D}$ is the result of a sample and hold device measuring at $+610 \mathrm{mV}$ during the electrical stimulation of the striatum. The arrow indicates the time of stimulation of striatum $(0.1 \mathrm{~ms}$ pulse width; $10 \mathrm{~V})$. Post calibration of the CFMe indicated that approximately $0.1 \mu \mathrm{M}$ dopamine is evoked by a single electrical stimulation in the dorsolateral striatum. Peak rise time is approximately $0.5 \mathrm{~s}$ and half decay time approximately $1.0 \mathrm{~s}$.

E. Placement of electrodes

Schematic diagram illustrating the placement of the carbon fibre microelectrode (recording electrode) and the bipolar stimulating electrodes (tip separation $200 \mu \mathrm{m}$ ) in the dorsolateral striatum. The carbon fibre electrode was placed 100 to $200 \mu \mathrm{m}$ from the bipolar stimulating electrodes most commonly in the region illustrated.

found to be linear in this range (see O'Neill and O’Connor, 2008).

\subsection{Experimental Protocols}

Single pulse dopamine was stimulated every $2 \mathrm{~min}$ during the course of the experiment. Every 30 min a multiple pulse stimulation protocol was carried out ( 5 pulses at $10 \mathrm{~Hz}$ ). Dopamine $\mathrm{D}_{2}$ antagonists have previously been shown to increase this signal (Limberger et al., 1991) but not by others (Trout and Kruk, 1992). Cumulative concentration response curves were carried out for each compound; 30 min baseline control, $30 \mathrm{~min} 100 \mathrm{nM}$, $30 \min 1 \mu \mathrm{M}$ and $30 \min 10 \mu \mathrm{M}$ compound. In a final set of experiments 2 concentrations of quinpirole (30 min each) were added after pretreatment of the brain slices for $30 \mathrm{~min}$ with either $10 \mu \mathrm{M}$ aripiprazole or -(3)-PPP. The maximum inhibition of dopamine release for each concentration of quinpirole was obtained from the average of the last two values during the $30 \mathrm{~min}$ perfusion.

\subsection{Drugs and Materials}

Artificial cerebrospinal fluid was prepared every day according to the following composition in $\mathrm{mM}$ : $\mathrm{NaCl}, 120 ; \mathrm{KCl}, 2.5 ; \mathrm{MgSO}_{4}, 2 ; \mathrm{CaCl}_{2}, 2$; $\mathrm{NaH}_{2} \mathrm{PO}_{4}, 1.25$ and D-glucose, $10 \mathrm{mM}$ in $\mathrm{H}_{2} \mathrm{O}$. It was bubbled with $95 \% \mathrm{O}_{2} / 5 \% \mathrm{CO}_{2}$. Aripiprazole was a gift from Dr. Paolo Cavanni, GSK, Verona. ()-3-PPP and quinpirole were obtained from Sigma (UK). Aripiprazole and (-)-3-PPP were dissolved in $100 \%$ dimethylsulphoxide to a concentration of $10^{-}$ ${ }^{2} \mathrm{M}$ and stored at $-20^{\circ} \mathrm{C}$ in $100 \mu \mathrm{L}$ volume containers. Dimethylsulphoxide final volume in aCSF was always $<0.05 \%$. Quinpirole was dissolved in artificial cerebrospinal fluid also to $10^{-2} \mathrm{M}$. All compounds were used within 5 days of preparation. Stock solutions of dimethylsulphoxide were made to obtain final bath concentrations of dimethylsulphoxide lower than $0.005 \%$ in the superfusing artificial cerebrospinal fluid. Solvent controls were carried out with similar dimethylsulphoxide controls. Previous experiments 
with $0.05 \%$ dimethylsulphoxide in the perfusing artificial cerebrospinal fluid did not affect single pulse dopamine release, rise time or decay time (Fig. 2; see also O’Neill \& O’Connor, 2008).

\subsection{Data analysis}

All sample and hold data were analyzed and peak release measured. These values were exported into excel sheets. Single pulse evoked dopamine over flow was measured as the peak release in response to electrical stimulation. Rise time and half decay time of dopamine release were measured in some of the experiments. Rise time was measured from the beginning of baseline to peak amplitude and half decay time was measured from peak release to $50 \%$ half decay. Stimulated dopamine release was measured over $6 \mathrm{~min}$ ( 3 stimulations) prior to the first test drug application and the average of these 3 values were taken as $100 \%$. All values prior and subsequent to these were represented as $\%$ control. Quinpirole $\mathrm{EC}_{50}$ curves were generated from the average \% inhibition (last 2 values) at the end of each $30 \mathrm{~min}$ application of quinpirole. $\mathrm{EC}_{50}$ values were calculated using the software package Graph Pad Prism $^{\text {тм }}$. Data are presented as means \pm standard error of the mean \pm (S.E.M.) of at least 4 independent experiments (different brain slices). Students t-test (paired and unpaired sampling where appropriate) was carried out at the individual time points indicated in the figures. $\mathrm{P}<0.05$ was considered significant.

A
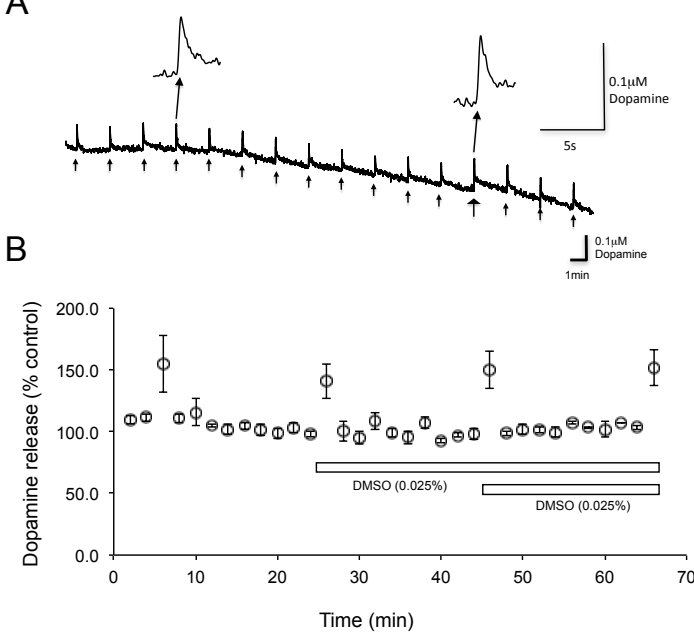

Figure 2. Control experiments carried out using fast cyclic voltammetry in slices of the rat striatum.

A. Typical sample and hold data trace showing stimulated $(10 \mathrm{~V}, 0.1 \mathrm{~ms})$ dopamine release every $2 \mathrm{~min}$ over a $30 \mathrm{~min}$ period. The trace has been subjected to triangular (Bartlett) window (width 15) filtering (Chart 6.1). The points of stimulation are indicated by the arrows. The larger arrow towards the end of the trace indicates that a multiple pulse stimulation ( 5 pulses at $10 \mathrm{~Hz}$ ) has been carried out. This was typically 1.5 to 1.7 times bigger than single pulse stimulation. Insets show on an extended time scale an example of a single pulse stimulated release of dopamine (left) and that of a 5 pulse stimulated response (right).

B. Averaged time course data showing the effect of $0.025 \%$ and $0.05 \% \mathrm{w} / \mathrm{v}$ DMSO on stimulated dopamine release. In the case of these experiments DMSO was applied over a $20 \mathrm{~min}$ time course. All subsequent experiments were carried out over multiples of $30 \mathrm{~min}$ time periods. The four larger points on the time course indicate the occurrence of the 5-pulse protocol. Peak dopamine release was measured from the base to maximum peak post stimulation using Chart Zoom and exported to Excel ${ }^{\mathrm{TM}}$. The average of the last 3 values prior to test application was taken as $100 \%$ and all values subsequent to these were represented as \% control (normalized). Data are presented as means \pm standard error of the mean (S.E.M.) of 4-7 independent experiments (different brain slices).

\section{RESULTS}

\subsection{Control experiments}

Single pulse dopamine release was evoked every 2 min $(10 \mathrm{~V} ; 0.1 \mathrm{~ms}$ duration) and was stable for more than 2 hr., Fig. 2A). Typically evoked single pulse dopamine release ranged from 0.05 to $0.12 \mu \mathrm{M}$ dopamine when measured against the calibrated electrode. Rise and decay times ranged from 0.5 to 0.75 and 0.5 to $1 \mathrm{~s}$ respectively. Application of the solvent DMSO, used for the test compounds, at concentrations of 0.025 and $0.05 \% \mathrm{~W} / \mathrm{V}$ had no effect on single pulse dopamine release (Fig. 2B). 5 pulses at $10 \mathrm{~Hz}$, multiple pulse stimulation, was evoked every $30 \mathrm{~min}$ and was also stable for more than $2 \mathrm{hr}$ (Fig. 2A and B). DMSO also had no significant effect on multiple pulse stimulation over this time period.

\subsection{Effects of Aripiprazole, PPP and quinpirole on single and multiple pulse evoked dopamine release}

Application of aripiprazole and (-)-3-PPP at concentrations ranging from $10^{-8} \mathrm{M}$ to $10^{-5} \mathrm{M}$ each for $30 \mathrm{~min}$, did not have any effect on single pulse evoked dopamine release (Fig. 3A and B respectively). Aripiprazole at $10 \mu \mathrm{M}$ but not 0.01 to $1.0 \mu \mathrm{M}$ significantly inhibited multiple pulse stimulated dopamine release $(5$ pulses at $10 \mathrm{~Hz}$; paired Student t-test; $* * \mathrm{P}<0.01$; Fig. $3 \mathrm{~A}$ ). Fig. $3 \mathrm{C}$ illustrates the inhibitory effect of quinpirole on single pulse dopamine release. Increasing concentrations of quinpirole (10 $\mathrm{nM}$ to $100 \mathrm{nM})$ were added to the brain slice chamber and complete inhibition of dopamine release occurred at $100 \mathrm{nM}$. An $\mathrm{EC}_{50}$ value of $32 \mathrm{nM}$ was calculated for quinpirole from the software package Graph Pad Prism $^{\mathrm{TM}}$. This is in agreement with other publications using this technique (see O'Neill et al., 2009).

\subsection{Effects of Aripiprazole and PPP on the inhibition of dopamine release by quinpirole}

Two concentrations of quinpirole (1 and $10 \mu \mathrm{M})$ were applied for $30 \mathrm{~min}$ to brain slices, which, had been pretreated with $10 \mu \mathrm{M}$ of either aripiprazole or (-)-3-PPP. Fig. 4A and B shows the averaged time course data showing the effect of 1.0 and $10 \mu \mathrm{M}$ 
quinpirole on stimulated dopamine release in the presence of $10 \mu \mathrm{M}$ aripiprazole (A) or (-)-3-PPP (B). $\mathrm{EC}_{50}$ values for quinpirole alone and in the presence of aripiprazole $(10 \mu \mathrm{M})$ were $38 \mathrm{nM}$ and $7.4 \mu \mathrm{M}$ respectively. This represents a 200 fold right-ward shift in the concentration response curve.
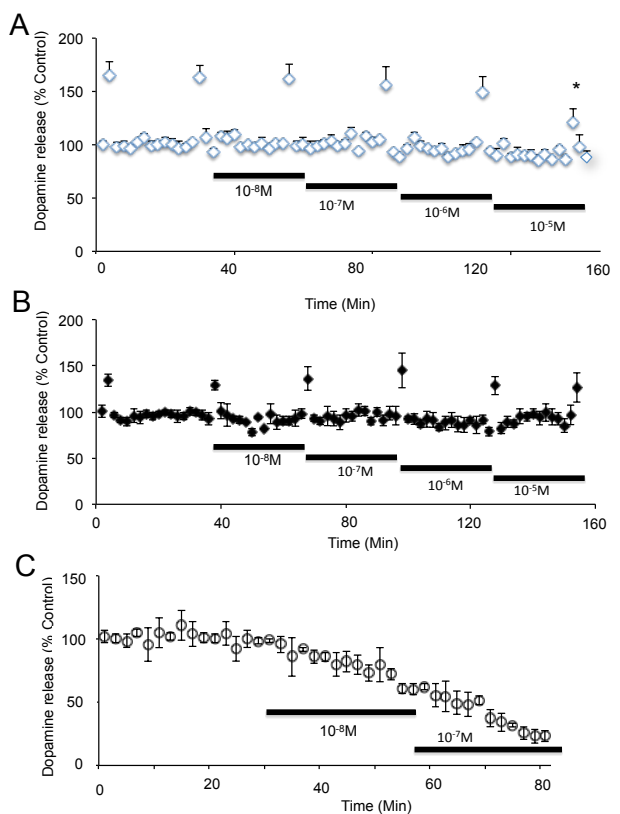

Figure 3. The effect of aripiprazole, 3-PPP and quinpirole on stimulated dopamine release in brain slices of the rat striatum.

A. Averaged time course data showing the effect of 0.01 , $0.1,1.0$ and $10 \mu \mathrm{M}$ aripiprazole on stimulated dopamine release. The upper four points represent the 5-pulse protocol every $30 \mathrm{~min}$. Aripiprazole did not have any effect on single pulse release at any of the concentrations. However 5 pulses at $10 \mathrm{~Hz}$ was significantly inhibited at $10 \mu \mathrm{M}$ only (paired Student t-test; ${ }^{*} \mathrm{P}<0.01 ; \mathrm{n}=4$ ).

B. Averaged time course data showing the effect of 0.01 , $0.1,1.0$ and $10 \mu \mathrm{M} 3$-PPP on stimulated dopamine release. The upper six points represent the 5-pulse protocol every $30 \mathrm{~min}$. 3-PPP did not have any effect on single or multiple pulse release at any of the concentrations tested.

C. Averaged time course data showing the effect of 10 and $100 \mathrm{nM}$ quinpirole on single pulse stimulated dopamine release. Quinpirole had a potent inhibitory effect on dopamine release with $10 \mathrm{nM}$ and $100 \mathrm{nM}$ inhibiting release by 25 and $85 \%$ respectively as previously reported.

In the presence of (-)-3-PPP the $\mathrm{EC}_{50}$ values were $38 \mathrm{nM}$ and 5.6 $\mu \mathrm{M}$ (a 150 fold shift; Fig. 4C and D respectively).

\section{DISCUSSION}

Using the technique of fast cyclic voltammetry it was expected that the agonist activity of dopamine compounds would manifest in an inhibition of single pulse stimulated dopamine release. On the other hand if a multiple pulse protocol was used to stimulate dopamine release and thus activate dopamine $\mathrm{D}_{2}$ autoreceptors, it might be expected that the antagonist activity of a test compound might increase stimulated dopamine release. Using FCV we also investigated if a partial antagonist applied at low concentrations might give rise to agonist activity alone whilst show antagonist activity at higher concentrations.

Surprisingly application of the standard dopamine $\mathrm{D}_{2}$ partial agonist aripiprazole had no significant effect on single pulse release at concentrations from $10 \mathrm{nM}$ to $10 \mu \mathrm{M}$. Aripiprazole is known to be very active at dopamine $\mathrm{D}_{2}$ receptors $\left(\mathrm{pEC}_{50} / \mathrm{pKi} \sim\right.$ 9.5/9.8) and a starting concentration of $10 \mathrm{nM}$ is greater than 10 fold higher than its $\mathrm{pEC}_{50}$ (Lawler et al., 1999). Therefore lower concentrations of this

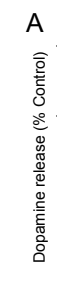
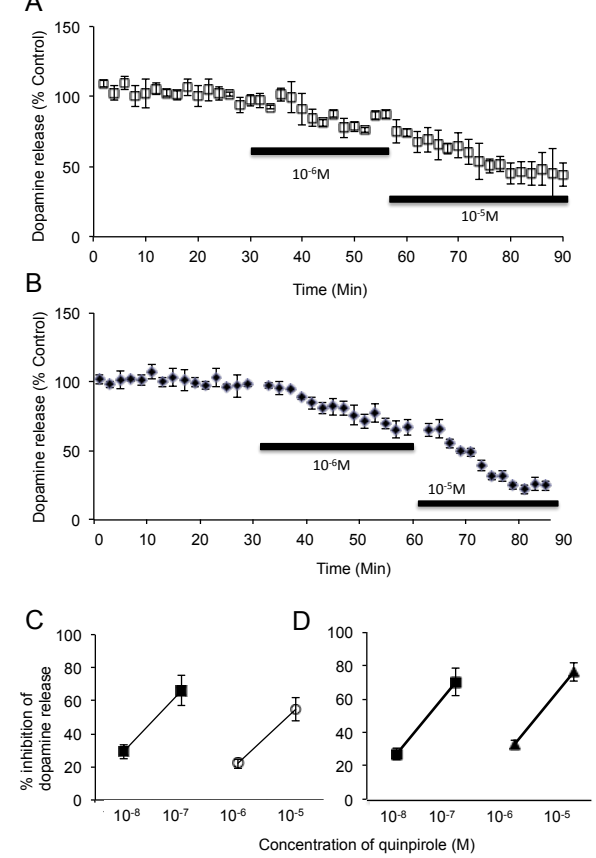

Figure 4. Effect of aripiprazole and 3-PPP in the presence of the dopamine $\mathrm{D}_{2}$ receptor agonist quinpirole on dopamine release.

A. Averaged time course data showing the effect of $1 \mu \mathrm{M}$ and $10 \mu \mathrm{M}$ quinpirole (indicated by black line bars) on stimulated dopamine release in the presence of $10 \mu \mathrm{M}$ aripiprazole (present throughout the experiment).

B. Averaged time course data showing the effect of $1 \mu \mathrm{M}$ and $10 \mu \mathrm{M}$ quinpirole (indicated by black line bars) on stimulated dopamine release in the presence of $10 \mu \mathrm{M} 3-$ PPP (present throughout the experiment). All data in A and $\mathrm{B}$ is presented as means \pm standard error of the mean (S.E.M.) of 4-5 independent experiments (different brain slices).

C. $\mathrm{EC}_{50}$ curves for the effect of quinpirole alone (0.01 and $0.1 \mu \mathrm{M}$; black squares, left) and quinpirole in the presence of aripiprazole $(10 \mu \mathrm{M}$, open circles; right) on single pulse dopamine release. $\mathrm{IC}_{50}$ values were estimated using the software package Graph Pad Prism ${ }^{\mathrm{TM}}$. There is an approximate 200-fold shift to the right of the curve in the presence of $10 \mu \mathrm{M}$ aripiprazole (see results section for values).

D. $\mathrm{EC}_{50}$ curves for the effect of quinpirole alone $(0.01$ and $0.1 \mu \mathrm{M}$; black squares, left) and quinpirole in the presence of 3-PPP $(10 \mu \mathrm{M}$, triangles; right) on single pulse dopamine release. There is an approximate 150 -fold shift to the right of the curve in the presence of $10 \mu \mathrm{M}$ aripiprazole. In both $\mathrm{C}$ and $\mathrm{D}$ results are expressed as percentage inhibition of dopamine release against log molar concentration of quinpirole. All data is presented as the mean of 4 to 7 independent experiments (different brain slices). 
partial agonist may be required to be tested (typically $<1 \mathrm{nM}$ ) to see an agonist effect. Therefore from these data alone we cannot determine if aripiprazole is a typical dopamine $\mathrm{D}_{2}$ agonist or a functionally selective dopamine $\mathrm{D}_{2}$ ligand. Another reason higher concentrations did not give rise to an inhibition of dopamine release may be that other receptors can be consistently occupied at that concentration (10 to $100 \mathrm{nM})$. For example aripiprazole at this concentration may have small but significant effects on dopamine $\mathrm{D}_{2}, \mathrm{D}_{3}, \mathrm{D}_{4}$, $5 \mathrm{HT}_{1 \mathrm{~A}} /{ }_{2 \mathrm{~A}} / 2 \mathrm{~B} / 2 \mathrm{C} / 7$, alpha ${ }_{1 \mathrm{~A}} /{ }_{1 \mathrm{~B}}$ and $\mathrm{H}_{1}$ receptors (Jordan et al., 2002). It is not known at this time if all of these receptors can directly or indirectly influence dopamine release. However in the region we are recording from it is unlikely that activation of all of these receptors plays a major role in the modulation of presynaptic dopamine release. Experiments using (-)-3-PPP (another known partial agonist) also did not detect inhibitory effects on single pulse dopamine release at $10 \mathrm{nM}, 100 \mathrm{nM}$ and $1 \mu \mathrm{M}$.

For both compounds the 5-pulse protocol, which was used to look at antagonist activity, did not show any significant increases in dopamine release in the presence of all four concentrations. This may be that the protocol is not suitable to observe these effects (see Limberger et al., 1991 and in contrast, Trout and Kruk, 1992). Longer stimulation protocols such as 10 or 20 pulses at 10 to $100 \mathrm{~Hz}$ would have detrimental effects on the concurrent single pulse experiments and these would have to be separated out. Therefore this protocol may not be as useful as an assessment of antagonist activity. Because of this it was decided to test the antagonist effects of the compounds on the inhibition of dopamine release by quinpirole.

Both compounds when present at $10 \mu \mathrm{M}$ caused an approximate 150 to 200 -fold shift to the right of the quinpirole concentration-response curve which compares favorably with the actions of other full antagonists at dopamine $\mathrm{D}_{2}$ receptors in previous work using this technique (Palij et. al., 1990; Bull and Sheehan, 1991 in both the rat striatum and nucleus accumbens). Our results were similar to the antagonistic effects of sulpiride, metoclopramide and clozapine.

The fact that aripiprazole can modulate in vivo 5$\mathrm{HT}$ and DA release in $\mathrm{mPFC}$ through the activation of 5- $\mathrm{HT}_{1 \mathrm{~A}}$ receptors may be a concern (Bortolozzi et al., 2007). These effects of aripiprazole in the cortex were through partial agonist activity at dopamine $\mathrm{D}_{2}$ autoreceptors and distinct from those of haloperidol. In a recent study a role for aripiprazole has been uncovered at dopamine $\mathrm{D}_{3}$ autoreceptors also (Tadori et al., 2008). We did not investigate its actions at these receptors in this study. The new generation antipsychotics including aripiprazole all seem to preferentially increase dopamine output in the nucleus accumbens as compared to the striatum (Hertel, 2006). It would be interesting to look at the effects of these agents in the nucleus accumbens. Partial agonist properties of aripiprazole were not revealed in studies carried out by Koener et al., (2011) using guanosine 5'-O- $(\gamma$ $\left[{ }^{35} \mathrm{~S}\right]$ thiotriphosphate $\left(\left[{ }^{35} \mathrm{~S}\right] \mathrm{GTP} \gamma \mathrm{S}\right)$ binding assays on striatal membranes from haloperidol-treated rats. This was also observed in behavioral assays. In fact aripiprazole behaved as an antagonist, efficiently inhibiting the functional response to dopamine.

In a micro-dialysis study by Oshibuchi et al., (2009), both aripiprazole and the full antagonist haloperidol equally suppressed increases in dopamine levels in fear conditioned rats. However only aripiprazole decreased tonic dopamine levels. This may indicate a differential effect of aripiprazole on tonic and phasic dopamine release. Whether aripiprazole is a typical dopamine $\mathrm{D}_{2}$ partial agonist, or a functionally selective dopamine $\mathrm{D}_{2}$ ligand, remains controversial (Urban et al., 2007). These authors have shown downstream signaling differences between aripiprazole and both quinpirole and (-)-3-PPP. Using G protein activation and prolactin release as a measure of dopamine $\mathrm{D}_{2}$ receptor activation, Cosi et al., (2006) showed that aripiprazole acted as a partial agonist at dopamine $\mathrm{D}_{2}$ receptors. It is also likely that sensitivity to aripiprazole is different between humans and rodents. In an interesting computer simulation report by Spiros et al., (2010), aripiprazole was tested at dopamine $\mathrm{D}_{2}$ receptors and predicted to have greater dopamine $D_{2}$ receptor antagonism in the human than in the rodent.

Our results also indicate competitive antagonism for the effects of (-)-3-PPP on the inhibition of dopamine release by quinpirole. Early reports on the activity of (-)-3-PPP at dopamine $\mathrm{D}_{2}$ receptors are also equivocal. Plantje et al. (1983; 1984), similar to our data, were able to demonstrate an antagonist effect of (-)-3-PPP in the rat striatum investigating the inhibition of $\mathrm{K}^{+}$-induced $\left[{ }^{3} \mathrm{H}\right]$ acetylcholine release caused by the dopamine $\mathrm{D}_{2}$ receptor agonist LY 141865. In the same year Markstein and Lahaye (1983) observed contrasting results where (-)-3-PPP did not inhibit electrically-evoked tritium overflow from rat striatal slices pre-incubated with $\left[{ }^{3} \mathrm{H}\right]$ dopamine. Arbilla and Langer (1984) investigated the action of both enantiomers of 3PPP on spontaneous and electrically evoked ${ }^{3} \mathrm{H}$ dopamine release in the striatum of rabbits. (+)-3PPP increased spontaneous dopamine overflow but inhibited electrically evoked dopamine release. In contrast to (+)-3-PPP, (-)-3-PPP increased electrically evoked dopamine release with no effect on spontaneous overflow. Furthermore similar to the findings presented here, (-)-3-PPP antagonized the inhibitory effect of apomorphine, damphetamine and (+)-3-PPP on evoked dopamine release. Finally Stamford et al., (1991) working in vivo and using a longer stimulation protocol observed increases in dopamine release in the striatum and nucleus accumbens in the presence of (-)-3-PPP. The (+) enantiomer presumable acting as a full agonist caused a decrease in release in the nucleus accumbens and little effect in the striatum. 


\section{Conclusion}

To date there has been equivocal data on the actions of both aripiprazole and (-)-3-PPP as partial agonists at dopamine $\mathrm{D}_{2}$ presynaptic autoreceptors. Our results indicate that whilst both compounds show little agonist activity on single pulse dopamine release at low and high concentrations, they have significant antagonistic properties at dopamine $\mathrm{D}_{2}$ auto-receptors.

\section{Acknowledgements}

We would like to thank P. Cavanni and C. Large for discussions on the work and M. Dalton for technical assistance.

\section{REFERENCES}

Arbilla, S., Langer, S.Z., 1984. Differential effects of the stereoisomers of 3PPP on dopaminergic and cholinergic neurotransmission in superfused slices of the corpus striatum. Naunyn Schmiedebergs Arch. Pharmacol 327, 6-13.

Armstrong-James, M., Millar, J., 1979, Carbon fibre microelectrodes. J Neurosci Methods 1, 279287.

Bortolozzi, A., Díaz-Mataix, L., Toth, M., Celada, P., Artigas, F., 2007. In vivo actions of aripiprazole on serotonergic and dopaminergic systems in rodent brain. Psychopharmacology (Berl) 191, 745-58.

Bull, D.R., Sheehan, M.J,. 1991. Presynaptic regulation of electrically evoked dopamine overflow in nucleus accumbens: a pharmacological study using fast cyclic voltammetry in vitro. Naunyn Schmiedebergs Arch. Pharmacol 343, 260-5.

Clark, D., Hjorth, S., Carlsson A., 1984. (+)- and (-)-3-PPP exhibit different intrinsic activity at striatal dopamine autoreceptors controlling dopamine synthesis. Eur. J. Pharmacol 106, 185-9.

Cosi, C., Carilla-Durand, E., Assié, M.B., Ormiere, A.M., Maraval, M., Leduc, N., NewmanTancredi, A., 2006. Partial agonist properties of the antipsychotics SSR181507, aripiprazole and bifeprunox at dopamine D2 receptors: G protein activation and prolactin release. Eur. J. Pharmacol 535, 135-144.

Hertel, P., 2006. Comparing sertindole to other new generation antipsychotics on preferential dopamine output in limbic versus striatal projection regions: mechanism of action. Synapse 60, 543-52.

Jordan, S., Koprivica, V., Chen, R., Tottori, K., Kikuchi, T., Altar, C.A., 2002. The antipsychotic aripiprazole is a potent, partial agonist at the human 5-HT1A receptor. Eur. J. Pharmacol 441, 137-140.

Koener, B., Goursaud, S., Van De Stadt, M., Calas, A.G., Jeanjean, A.P., Maloteaux, J.M., Hermans, E., 2011. Pharmacological blockade of dopamine $D_{2}$ receptors by aripiprazole is not associated with striatal sensitization. Naunyn Schmiedebergs Arch. Pharmacol 383, 65-77.

Kruk, Z.L., O'Connor, J.J., 1995. Fast electrochemical studies in isolated tissues. Trends Pharmacol. Sci 16, 145-149.

Lawler, C.P., Prioleau, C., Lewis, M.M., Mak, C., Jiang, D., Schetz, J.A., Gonzalez, A.M., Sibley, D.R., Mailman, R.B., 1999. Interactions of the novel antipsychotic aripiprazole (OPC-14597) with dopamine and serotonin receptor subtypes. Neuropsychopharmacology 20, 612-27.

Limberger, N., Trout, S.J., Kruk, Z.L., Starke, K., 1991. "Real time" measurement of endogenous dopamine release during short trains of pulses in slices of rat neostriatum and nucleus accumbens: role of autoinhibition. Naunyn Schmiedebergs Arch. Pharmacol 344, 623-9.

Markstein, R., Lahaye, D., 1983. In vitro effect of the racemic mixture and the (-) enantiomer of $\mathrm{N}-$ n-propyl-3-(3-hydroxyphenyl)-piperidine (3PPP) on postsynaptic dopamine receptors and on a presynaptic dopamine autoreceptor. J. Neural. Transm 58, 43-53.

Millar, J., Barnett, T.G., $1988 . \quad$ Basic instrumentation for fast cyclic voltammetry. J Neurosci Methods 25, 91-95.

Mulder, A.H., Draper, R., Sminia, P., Schoffelmeer, A.N., Stoof, J.C., 1985. Agonist and antagonist effects of 3-PPP enantiomers on functional dopamine autoreceptors and postsynaptic dopamine receptors in vitro. Eur. J. Pharmacol 107, 291-7.

Muralikrishnan, D., Ebadi, M., Brown-Borg, H.M., 2004. Dopamine agonist 3-PPP fails to protect against MPTP-induced toxicity. Neurochem. Res 29, 379-84.

O'Connor, J.J., Kruk, Z.L., 1991. Fast cyclic voltammetry can be used to measure stimulated endogenous 5-hydroxytryptamine release in untreated rat brain slices. J Neurosci Methods. $38,25-33$.

O'Connor, J.J., Kruk, Z.L., 1992. Pharmacological characteristics of 5-hydroxytryptamine autoreceptors in rat brain slices incorporating the dorsal raphe or the suprachiasmatic nucleus. $\mathrm{Br} \mathrm{J}$ Pharmacol 106, 524-532.

O’Neill, C., O’Connor, J.J., 2008. An investigation into the influence of NMDA and GABA on the modulation of electrically stimulated dopamine release by adenosine in the rat striatum: studies using fast cyclic voltammetry. Sensors 8, 52295237.

O'Neill, C., Evers-Donnelly, A., Nicholson, D., O'Boyle, K.M., O'Connor, J.J., 2009. D2 receptor-mediated inhibition of dopamine release in the rat striatum in vitro is modulated by $\mathrm{CB} 1$ receptors: studies using fast cyclic voltammetry. J Neurochem 108, 545-551.

Oshibuchi, H., Inada, K., Sugawara, H., Ishigooka, J., 2009. Aripiprazole and haloperidol suppress excessive dopamine release in the amygdala in response to conditioned fear stress, but show 
contrasting effects on basal dopamine release in methamphetamine-sensitized rats. Eur. J. Pharmacol 615, 83-90.

Palij, P., Bull, D.R., Sheehan, M.J., Millar, J., Stamford, J., Kruk, Z.L., Humphrey, P.P., 1990. Presynaptic regulation of dopamine release in corpus striatum monitored in vitro in real time by fast cyclic voltammetry. Brain Res 509, 172174.

Plantjé, J.F., Hansen, H.A., Daus, F.J., Stoof, J.C., 1984. The effects of SCH 23390, YM 09151-2, (+)- and (-)-3-PPP and some classical neuroleptics on D-1 and D-2 receptors in rat neostriatum in vitro. Eur. J. Pharmacol 105, 7383.

Plantjé, J.F., Mulder, A.H., Stoof, J.C., 1983. 3-PPP antagonizes the in vitro effects of D-1 and D-2 dopamine receptor agonists in rat neostriatum. Eur. J. Pharmacol 91, 317-320.

Spiros, A., Carr, R., Geerts, H., 2010. Not all partial dopamine $\mathrm{D}(2)$ receptor agonists are the same in treating schizophrenia. Exploring the effects of bifeprunox and aripiprazole using a computer model of a primate striatal dopaminergic synapse. Neuropsychiatr. Dis. Treat 6, 589-603.

Stamford, J.A., 1990. Fast cyclic voltammetry: measuring transmitter release in 'real time'. J Neurosci Methods 34, 67-72.
Stamford, J.A., Kruk, Z.L., Millar, J., 1991. Differential effects of dopamine agonists upon stimulated limbic and striatal dopamine release: in vivo voltammetric data. Br. J. Pharmacol 102, 45-50.

Tadori, Y., Forbes, R.A., McQuade, R.D., Kikuchi, T., 2008. Characterization of aripiprazole partial agonist activity at human dopamine D3 receptors. Eur. J. Pharmacol 597, 27-33.

Trout, S.J., Kruk, Z.L., 1992. Differences in evoked dopamine efflux in rat caudate putamen, nucleus accumbens and tuberculum olfactorium in the absence of uptake inhibition: influence of autoreceptors. Br. J. Pharmacol 106, 452-8.

Urban, J.D., Vargas, G.A, von Zastrow, M., Mailman, R.B., 2007. Aripiprazole has functionally selective actions at dopamine D2 receptor-mediated signaling pathways. Neuropsychopharmacology 32, 67-77.

Zocchi, A., Fabbri, D., Heidbreder, C.A., 2005. Aripiprazole increases dopamine but not noradrenaline and serotonin levels in the mouse prefrontal cortex. Neurosci. Lett 387, 157-161. 